\title{
Formation kinetics of the pink azo dye in the determination of nitrite in natural waters
}

\author{
SU-CHENG PAI and CHUNG-CHENG YANG \\ Institute of Oceanography, Natıonal Taiwan University, Taipet (Tatwan) \\ JOHN P RILEY * \\ Oceanography Laboratories, Department of Earth Sclences, University of Liverpool, Liverpool (UK)
}

(Recelved 8th November 1989)

\begin{abstract}
The kinetics of the reaction for the formation of the pink azo dye in the determination of nitrite in both fresh water and sea water was studied at different acidities, temperatures, and concentrations of $N$-1-naphthylethylencdiamine (NED). It was found that the reaction is considerably faster in sea water than in fresh water, and that increase in the acidity slightly increases the molar absorptivity A concentration of NED $\left(4.29 \times 10^{-6} \mathrm{M}\right)$ between the extremes described in the literature and $42 \times 10^{-3} \mathrm{M}$ sulphanilamide are recommended for both manual determination and flow-injection analysis with respect to rapid reaction and a low reagent blank
\end{abstract}

Nitrite is usually determined in natural waters, including sea water, by modifications of the classical Greiss-Ilosvay technique. Nitrite is reacted with an aromatic primary amine and the resulting diazonium ion is coupled with another aromatic amine to give a pink azo dye, the absorbance of which is measured. Most workers now use methods based on a reagent combination of sulphanilamide and $N$-1-naphthylethylenediamine (NED), first suggested by Shinn [1]. They have the advantages of simplicity, sensitivity and speed, complete reaction being achieved in a few minutes at room temperature. There are considerable differences between the ratios of the concentrations of the reagents which have been used in the various published procedures. However, very little attention has been paid to the kinetics of colour formation and to those factors which affect them, probably owing to the excellent performance of the method.

Reaction kinetics become very important if the method is adapted to flow-injection analysis, as in most instances the time allowed for the sample to react with reagents in the manifold is much shorter than in manual procedures. As a consequence, colour development is frequently not complete by the time the sample reaches the detection device. In the authors' experience, many factors affect the final response in flow-injection analysis for nitrite, including reagent concentrations, acidity, temperature and the salt matrix. The effects of variations of these factors have been studied in a series of batch experiments in which the formation of the azo dye was monitored using a dipping probe colorimeter following addition of the NED reagent (kinetics of the initial diazotization reaction 
were not examined as the reaction is very rapid). The examination of the results enabled the conditions for the coupling reaction to be optimized so that the procedure could be adapted for flow-injection analysis.

\section{EXPERIMENTAL}

\section{Reagents}

A $1 \%(\mathrm{w} / \mathrm{v})$ solution of sulphanilamide reagent (SUL) was prepared by dissolving $1 \mathrm{~g}$ of sulphanilamide in $10 \mathrm{ml}$ of $2.5 \mathrm{M}$ hydrochloric acid and diluting to $100 \mathrm{ml}$ with water. A $0.1 \%$ (w/v) solution of $N$-1-naphthylethylenediamine reagent (NED) was prepared by dissolving $0.1 \mathrm{~g}$ of NED in $100 \mathrm{ml}$ of water. A stock standard nitrite solution $\left(2.5 \mathrm{mmol}^{-1}\right)$ was prepared by dissolving $0.1725 \mathrm{~g}$ of sodium nitrite in 11 of distilled water. It was used to prepare a working standard solution in which $1 \mathrm{ml}=0.25 \mu \mathrm{mol} \mathrm{NO}-$.

A freshly collected and filtered sample of coastal sea water was stored in a polyethylene bottle until required. Its nitrite content was found to be ca. $0.2 \mu \mathrm{M}$.

\section{Instruments}

Colour formation was monitored with a Brinkman PC-800 dipping probe colorimeter with a light path equivalent to $1 \mathrm{~cm}$ and fitted with a filter having its maximum transmission at $540 \mathrm{~nm}$. The probe was mounted in a magnetically stirred reaction vessel which consisted of a modified Pyrex beaker which was mounted in a thermostatically controlled bath $\left( \pm 2^{\circ} \mathrm{C}\right)$. The readings from the colorimeter were checked periodically by measuring the absorbance of the solution with a Shimadzu 2100 double-beam spectrophotometer at the same wavelength, after colour development was complete.

\section{Procedure}

To the dry Pyrex beaker were added consecutively $1 \mathrm{ml}$ of working standard solution (0.25 $\mu \mathrm{mol}$ of $\left.\mathrm{NO}_{2}^{-}\right),(47-x-y) \mathrm{ml}$ of distilled water [or $40 \mathrm{ml}$ of sea water and $(7-x-y) \mathrm{ml}$ of distilled water] and $x \mathrm{ml}$ of $0.25 \mathrm{M}$ hydrochloric acid. When the solution had reached the desired temperature, $1 \mathrm{ml}$ of SUL reagent was added. The mixture was stirred for $3 \mathrm{~min}$ and $y \mathrm{ml}$ of NED reagent was then added rapidly. The recorder was immediately switched on and the change in absorbance with time was recorded.

For experiments at high temperatures, the water was preheated to a temperature higher than the desired value using a microwave oven, and then allowed to cool to the desired temperature. This eliminated problems of bubble formation.

\section{RESULTS AND DISCUSSION}

\section{Effect of acidity}

The effects of vanation of the acidity on the formation of the azo dye were monitored for 10 min in 40-ml samples of fresh water and sea water, both spiked with $0.25 \mu \mathrm{mol}$ of nitrite, after adding the reagents and then diluting with water to a final volume of $50 \mathrm{ml}$. The final acidity ranged from 0.005 to $0.045 \mathrm{M}$ at intervals of 0.005 $M$, whereas the final concentrations of NED and SUL reagents were fixed at $77 \mu \mathrm{M}$ and $1.1 \mathrm{mM}$, respectively.

The absorbance vs. time curves were all exponential, corresponding with the equation of $A=A_{\max }[1-\exp (-k t)]$, where $A_{\max }$ and $A$ are the absorbances at the end of the reaction and at time $t$ respectively; contour plots from the data are shown in Fig. 1a and b. Allowance was made for the nitrite originally present in the sea water and blanks were deducted. It was found that the apparent molar absorptivity for both fresh water and sea water were almost identical at the same acidity, but tended to increase with increasing acidity (see Table 1). At an acidity of $0.005 \mathrm{M}$ the value was ca. $440001 \mathrm{~mol}^{-1} \mathrm{~cm}^{-1}$ at $540-543 \mathrm{~nm}$, whereas it was $504001 \mathrm{~mol}^{-1} \mathrm{~cm}^{-1}$ at $0.025 \mathrm{M}$ and $516001 \mathrm{~mol}^{-1} \mathrm{~cm}^{-1}$ at $0.045 \mathrm{M}$. The values found at the higher acidities in this experiment were similar but slightly higher than that suggested by Parsons et al. [2] and Strickland and Parsons [3], who gave an empirical factor equivalent to a molar absorptivity of ca. $48000 \mathrm{l} \mathrm{mol}^{-1}$ $\mathrm{cm}^{-1}$ at $540 \mathrm{~nm}$ at an acidity of $0.023 \mathrm{M}$. However, the value for similar acidities was found to be $8 \%$ higher than that given by Grasshoff et al. 

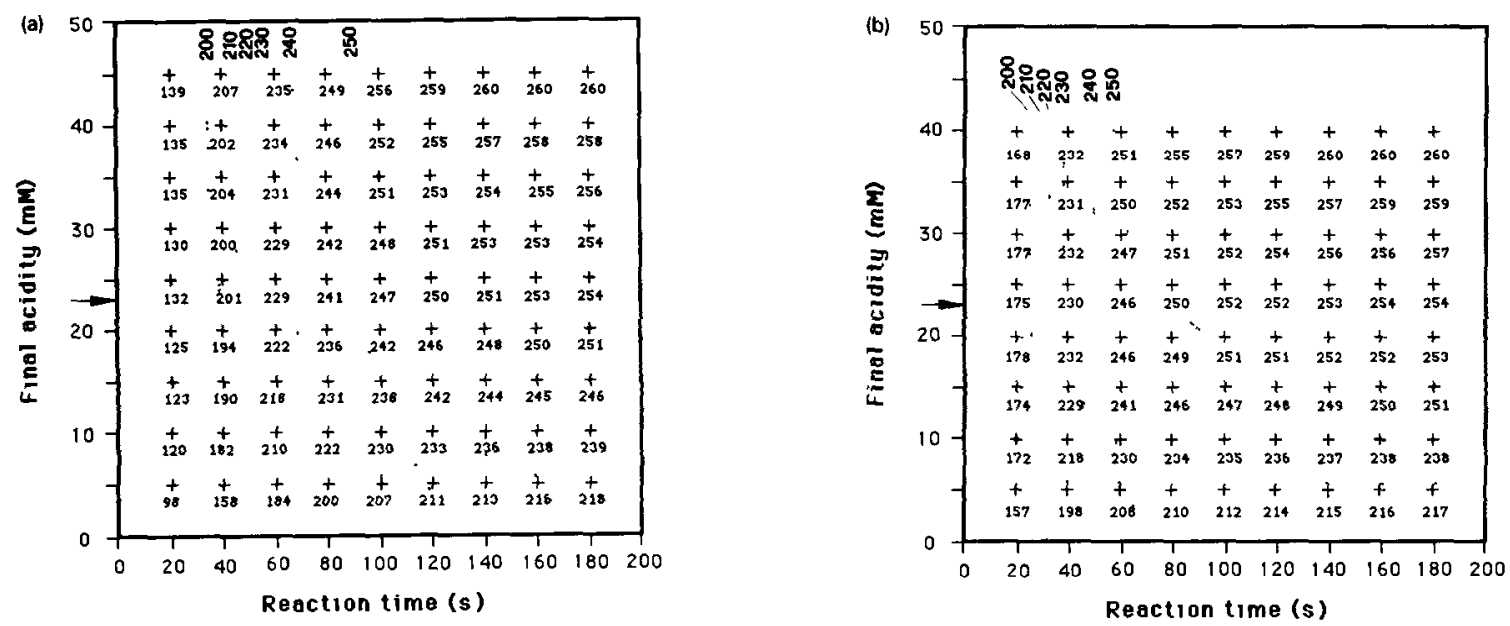

Fig. 1. Contour plots to emphasize the effect of final acidity on the formation of the pink azo dye Data points (absorbance $\times 10^{3}$ ) were digitized from the colour formation curves. The arrow marks the acidity suggested by Strickland and Parsons [3]. The final concentrations of nitnte, SUL and NED were $5 \mu \mathrm{M}, 1.1 \mathrm{mM}$ and $77 \mu \mathrm{M}$, respectively. (a) Fresh water; (b) sea water. Temperature, $29^{\circ} \mathrm{C}$.

[4], who gave a value of $460001 \mathrm{~mol}^{-1} \mathrm{~cm}^{-1}$ at $543 \mathrm{~nm}$ at an acidity of $0.023 \mathrm{M}$.

It is evident from Fig. 1 that the rate of colour formation in the sea-water samples was considerably faster than in the fresh-water samples at all acidities. The average time for $90 \%$ colour development, $t(90 \%)$, was $60 \pm 3 \mathrm{~s}$ in fresh water at acidities above $10 \mathrm{mM}$, compared with $40 \pm 2 \mathrm{~s}$ in sea water at all acidities (Table 1). Variation of the

\section{TABLE 1}

Molar absorptivities ( $\epsilon$ ) of the pink azo dye and times required for $90 \%$ colour development at various acidities at $29^{\circ} \mathrm{C}$

\begin{tabular}{|c|c|c|c|}
\hline \multirow{2}{*}{$\begin{array}{l}\text { Acidity } \\
\text { (mM) }\end{array}$} & \multirow{2}{*}{$\begin{array}{l}\in(540 \mathrm{~nm})^{a} \\
\left(1 \mathrm{~mol}^{-1} \mathrm{~cm}^{-1}\right)\end{array}$} & \multicolumn{2}{|l|}{$t(90 \%)(\mathrm{s})$} \\
\hline & & Fresh water & Sea water \\
\hline 5 & 44000 & 70 & 40 \\
\hline 10 & 48400 & 65 & 40 \\
\hline 15 & 49600 & 63 & 39 \\
\hline 20 & 50000 & 63 & 39 \\
\hline 25 & 50400 & 60 & 40 \\
\hline 30 & 50700 & 58 & 39 \\
\hline 35 & 50900 & 58 & 39 \\
\hline 40 & 51200 & 59 & 40 \\
\hline 45 & 51400 & 58 & 40 \\
\hline
\end{tabular}

a Measurements were made with a Shimadzu 2100 double-beam spectrophotometer using a $1-\mathrm{cm}$ cell $10 \mathrm{~min}$ after adding the NED reagent. The $\epsilon$ values were calculated after deduction of the reagent blank. final acidity produced no significant effect on the rate of colour development. However, the molar absorptivity increased by $12.7 \%$ as the acidity was increased from 5 to $15 \mathrm{mM}$ (Table 1). Simultaneously, the wavelength of maximum absorption increased slightly. Further increases in the acidity led to only minor increases in molar absorptivity.

\section{Effect of NED concentration}

The effect of the concentration of NED on the rate of colour development from $5 \mu \mathrm{M}$ nitrite was

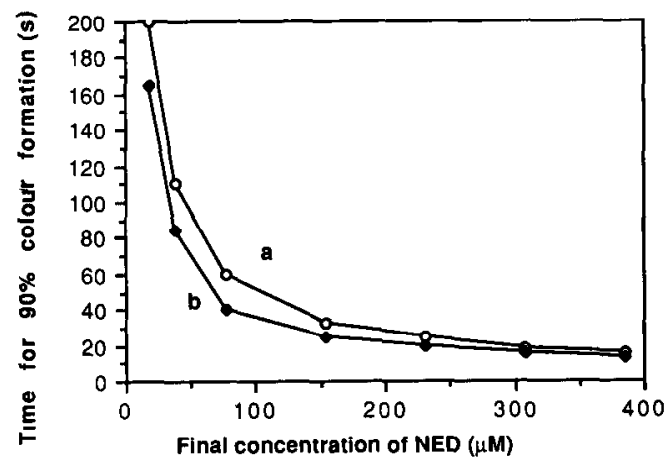

Fig. 2. Time required for $90 \%$ colour formation with a sample containing $0.25 \mu \mathrm{mol}$ of nitrite at various concentrations of NED at $29^{\circ} \mathrm{C}$. The funal acidity was $25 \mathrm{mM}$ and the concentration of SUL was $1.1 \mathrm{mM}$. (a) Fresh water; (b) sea water. 


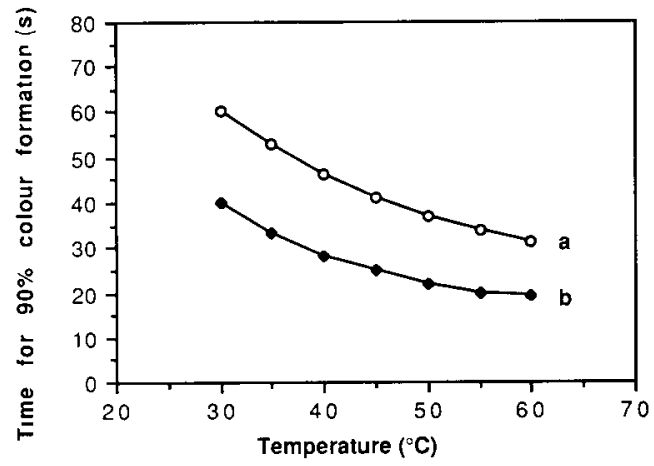

Fig. 3 Time required for $90 \%$ colour formation with a sample containing $0.25 \mu \mathrm{mol}$ of nitrite at different temperatures The final acidity, [SUL] and [NED] were kept constant at $25 \mathrm{mM}$, $11 \mathrm{mM}$ and $77 \mu \mathrm{M}$, respectively. (a) Fresh water; (b) sea water

measured at a final acidity of $0.025 \mathrm{M}$ and 1.1 mM SUL. It was found (Fig. 2) that the time required for $90 \%$ colour development bears a hyperbolic relationship to the NED concentration, suggesting a first-order reaction. The values of $t(90 \%)$ for sea water were only ca. $75 \%$ of those for fresh water. ment

Effect of temperature on rate of colour develop-

The tıme for $90 \%$ colour development was measured over the range $29-60^{\circ} \mathrm{C}$ under constant conditions (acidity $0.025 \mathrm{M}$; [SUL] $1.1 \mathrm{mM}$; [NED] $77 \mu \mathrm{M}$ ). The results (Fig. 3) show that the rate of colour development can be efficiently enhanced by an increase in temperature. In flow-injection analysis, the resolution of the peak could be im- proved if the manifold were to be equipped with a heating bath. In practice, however, problems are likely to occur in the photometry stage as a result of bubble formation if temperatures in excess of $50^{\circ} \mathrm{C}$ are used. For this reason it is preferable to speed up the reaction by increasing the concentration of NED rather than by raising the temperature.

\section{DISCUSSION}

The reagent conditions laid down in several standard manual nitrite methods are given in Table 2, from which it can be seen that the final NED concentrations used range from 74 to 148 $\mu \mathrm{M}$. These correspond to $t(90 \%)$ values for fresh water and sea water (In parentheses) of 63 (44) and 35 (28) s, respectively (Fig. 2). These differences in the rates of colour development are, of course, of no consequence in manual methods. In flow-injection analysis, however, an optimum photometric response can only be achieved if the reactions can be made very rapid. Hence, the NED concentration will play a key role in deciding the peak response. In fact, very high NED concentrations (up to $1342 \mu \mathrm{M}$ ) have been recommended in several of the published flow-injection procedures (Table 3 ), even though they always lead to high reagent blanks. Consideration of the data in Figs. 1 and 2 led to the conclusion that the flow-injection determination of nitrite could be carried out using a much lower final concentration

\section{TABLE 2}

Companison of reagent concentrations in standard manual procedures for the determination of nitrite

\begin{tabular}{|c|c|c|c|c|c|c|}
\hline \multirow[t]{2}{*}{ Parameter } & \multicolumn{6}{|c|}{ Reference } \\
\hline & [5] & [3] & {$[6]^{a}$} & [7] $^{\mathrm{b}}$ & [4] & [8] \\
\hline Sample volume (ml) & 40 & 50 & 50 & 50 & 50 & 40 \\
\hline Reagent volume (ml) & 2 & 2 & 2 & 2 & 2 & 1 \\
\hline Fınal volume $(\mathrm{ml})$ & 50 & 52 & 52 & 52 & 52 & 50 \\
\hline Wavelength (nm) & 543 & 543 & 540 & 543 & 540 & 540 \\
\hline Acıdity (mM) & 28 & 23 & 97 & 23 & 23 & 45 \\
\hline [SUL] $(\mathrm{mM})$ & 1.4 & 1.1 & 2.2 & 11 & 11 & 4.6 \\
\hline$[\mathrm{NED}](\mu \mathrm{M})$ & 92 & 74 & 148 & 74 & 74 & 150 \\
\hline
\end{tabular}

a Method 354.1. ${ }^{\mathrm{b}}$ Method 419. 
TABLE 3

Comparison of final SUL and NED concentrations in automated procedures for the determination of nitrite

\begin{tabular}{|c|c|c|c|c|c|c|c|c|c|}
\hline \multirow[t]{3}{*}{ Parameter } & \multicolumn{9}{|c|}{ Reference } \\
\hline & \multicolumn{2}{|c|}{$[6]^{a}$} & \multicolumn{2}{|l|}{$[6]^{b}$} & \multicolumn{2}{|l|}{$[7]^{c}$} & \multirow[t]{2}{*}{ [9] } & \multirow[t]{2}{*}[10]{} & \multirow[t]{2}{*}[11]{} \\
\hline & $I^{d}$ & II ${ }^{d}$ & $I^{d}$ & II $^{d}$ & $\mathrm{I}^{\mathrm{d}}$ & II ${ }^{d}$ & & & \\
\hline Acıdity (mM) & $p^{e}$ & $\mathrm{p}$ & $\mathbf{p}$ & $\mathrm{p}$ & $\mathrm{p}$ & $\mathbf{p}$ & 150 & 200 & $\mathbf{p}$ \\
\hline [SUL] $(\mathbf{m M})$ & 6.2 & 11.6 & 30.3 & 40.4 & 303 & 40.4 & 139 & 9.7 & 25.9 \\
\hline$[\mathrm{NED}](\mu \mathrm{M})$ & 331 & 617 & 1007 & 1342 & 1007 & 1342 & 924 & 643 & 859 \\
\hline
\end{tabular}

Method 353.1. ${ }^{b}$ Method 353.2. ${ }^{\mathrm{c}}$ Method 418F. ${ }^{\mathrm{d}}$ I and II = nitrate-nitrite manifolds for Automated System I and II, respectively. 'p: Phosphoric acid rather than $\mathrm{HCl}$ is used.

(o)

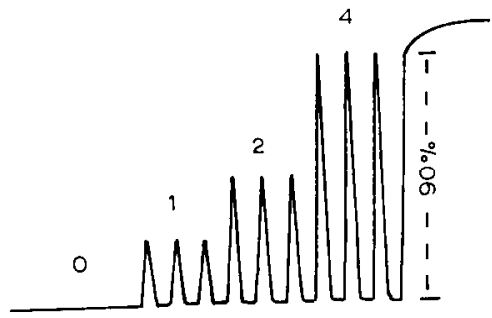

(b)

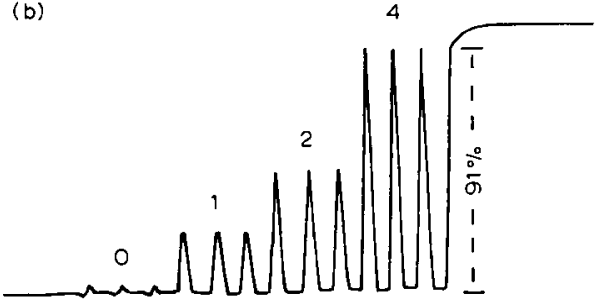

Fig. 4. Peaks for determination of $0,1,2$ and $4 \mu \mathrm{M}$ nitrite in fresh and sea water by flow-injection analysis using the recommended reagent concentrations and flow-rates, compared with the stopped-flow signal for $4 \mu \mathrm{M}$ nitrite (a) Fresh water; (b) sea water.

of NED. It was found (Fig. 4), using the stop-flow technique, that $90 \%$ colour development could be attained in 10-15 s with both fresh and sea water in a flow-injection manifold with final conditions of acidity $67 \mathrm{mM}$ and SUL and NED concentrations of $4.2 \mathrm{mM}$ and $4.29 \mu \mathrm{M}$, respectively. This was achieved by use of a $2 \%$ solution of SUL in $15 \%$ hydrochloric acid and a $0.3 \%$ solution of
NED and a flow-rate ratio of $2.5: 0.1: 0.1$ (sample : SUL: NED).

The authors thank Mr. Liang-Saw Wen and Mr. Chun-Mao Tseng for their kind assistance with the experimental work. This project was sponsored by the National Science Council of the Republic of China, under contact number NSC7902009-002a-05.

\section{REFERENCES}

1 M.R. Shinn, Ind. Eng. Chem, Anal Ed., 13 (1941) 330

2 T.R. Parsons, Y. Maita and CM. Lall, A Manual of Chemical and Biological Methods for Seawater Analysis, Pergamon, Oxford, 1984, p. 22.

3 J D H Strickland and T.R. Parsons, A Practıcal Handbook for Analysis of Seawater, Fishenes Research Board of Canada, Ottawa, 1972, p. 77

4 K. Grasshoff, in K. Grasshoff, M. Ehrhardt and K Kremling (Eds.), Methods of Seawater Analysıs, 2nd edn., Verlag Chemıe, Weinheim, 1983, p. 139.

$5 \mathrm{~K}$ Bendschneider and R.J. Robınson, J Mar Res., 11 (1952) 97

6 Environmental Protection Agency, Method 354 1, 1971, Methods 353.1 and 353.2, 1978

7 Standard Methods for the Examination of Water and Wastewater, 15th ed., Amencan Public Health Association, Washıngton, DC, 1981, p 380

8 Standing Committee of Analyts, Methods for the Examination of Waters and Associated Materials Oxidized Nitrogen in Waters (1981) HM Stationery Office, London, 1981,

9 L. Anderson, Anal. Chım. Acta, 110 (1979) 123

10 K S Johnson and R.L. Petty, Limnol. Oceanogr, 28 (1983) 1260

11 J F. van Staden, Anal. Chım. Acta, 138 (1982) 403 